\title{
Molecular Phylogenetic Analysis of Nitrobacter spp. STÉPHANIE ORSO,${ }^{1 *}$ MANOLO GOUY,${ }^{2}$ ELISABETH NAVARRO,${ }^{1} \dagger$ AND PHILIPPE NORMAND ${ }^{1}$ Laboratoire d'Ecologie Microbienne, URA CNRS 1450, ${ }^{1}$ and Laboratoire de Biométrie, URA CNRS 143, ${ }^{2}$ Université Claude-Bernard-Lyon I, 69622 Villeurbanne Cedex, France
}

\begin{abstract}
The phylogeny of bacteria belonging to the genus Nitrobacter was investigated by sequencing the whole $16 \mathrm{~S}$ rRNA gene. The average level of similarity for the three Nitrobacter strains examined was high $(99.2 \%)$, and the similarity level between Nitrobacter winogradskyi and Nitrobacter sp. strain $L L$, which represent two

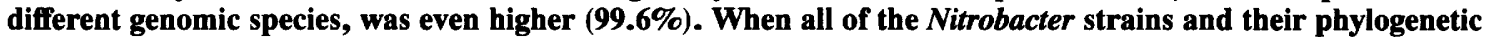
neighbors Bradyrhizobium and Rhodopseudomonas species were considered, the average similarity level was 98.1\%. When complete sequences were used, Nitrobacter hamburgensis clustered with the two other Nitrobacter strains, while this was not the case when partial sequences were used. The two Rhodopseudomonas palustris strains examined exhibited a low similarity level $(97.6 \%)$ and were not clustered.
\end{abstract}

Bacteria belonging to the genus Nitrobacter constitute a key part of the nitrification process as they are the only nitrite-oxidizing microorganisms known to occur in soil. Until now, this chemical process has been studied more than the microorganisms themselves because of difficulties in isolating and cultivating the bacteria $(4,13,17)$.

Nevertheless, workers have performed taxonomic studies to classify the few strains that have been isolated and to relate serological and physiological characteristics to genomic differences. Initially, taxonomic studies started with observations of morphological features, and currently the taxonomy of the genus Nitrobacter is still largely based on such criteria (24). However, morphological criteria are often considered inappropriate for defining natural relationships, particularly when microorganisms are concerned. Because of such limitations, genomic methods, such as DNA-DNA hybridization and 16S rRNA oligonucleotide cataloging, have been used $(13,20)$. These methods permitted demonstration that the genus Nitrobacter belongs to the alpha subdivision of the Proteobacteria (21), which includes, among other taxa, the genus Bradyrhizobium and the species Rhodopseudomonas palustris, which are known to be phylogenetically very closely related to the genus Nitrobacter $(5,8,20)$. Recent DNA-DNA hybridization data permitted division of the genus Nitrobacter into three genomic species; genomic species 1 contains type strain of Nitrobacter winogradskyi, genomic species 3 corresponds to Nitrobacter hamburgensis, and genomic species 2 contains proposed reference strain LL (13).

Among the genomic methods used, nucleic acid sequencing is certainly the technique which has most revolutionized microbiology; this technique has been shown to be a powerful tool for exploring the phylogeny of both prokaryotes and eukaryotes (27). As a result, microorganisms are now characterized not only on the basis of their phenotypic features but also with an evolutionary perspective. The phylogenetic aspect of bacterial characterization is becoming an increasingly important step, even a necessary one for

\footnotetext{
* Corresponding author. Mailing address: Laboratoire d'Ecologie Microbienne, URA CNRS 1450, Université Claude-Bernard-Lyon I, 43 boulevard du 11 Novembre 1918, 69622 Villeurbanne Cedex, France. Phone: 724482 89. Fax: 724312 23. Electronic mail address: orso@ecosol.univ-lyon1.fr.

† Present address: Laboratoire de Microbiologie, Centre ORSTOM de Nouméa, BP A5 Nouméa Cedex, New Caledonia.
}

any microbial taxonomic study. Several molecules have been used as a molecular clock, but the 16S rRNA gene has received most attention because of its highly conserved and ubiquitous nature (27).

The aim of this work was to sequence the 16S rRNAs of Nitrobacter spp. strains, primarily to investigate the phylogeny of the genus Nitrobacter and its relatives. Recently, Young et al. (28) have confirmed, by using partial 16S rRNA gene sequences, the phylogenetic relatedness of $\boldsymbol{R}$. palustris and Bradyrhizobium japonicum. As this conclusion agreed with previous results and as data from other work hinted that sequencing only a part of the $16 \mathrm{~S}$ rRNA molecule could be sufficient to establish a correct phylogeny $(7,11,22)$, we determined the sequence of a 16S rRNA gene segment for the type strains of the three Nitrobacter genomic species and for the type strain of $R$. palustris. However, the partial sequences revealed too few substitutions in the different strains for oligonucleotide probe construction, the ultimate aim of our work. We therefore determined the whole $16 \mathrm{~S}$ rRNA sequence and compared the resulting phylogeny with the DNA-DNA hybridization data published recently (13).

\section{MATERIALS AND METHODS}

Bacterial strains. The bacterial strains used in this study are listed in Table 1. The strains were grown and DNA was extracted as described previously (14).

DNA amplification. The 16S rRNA genes were amplified by the PCR (12) by using the following two prokaryotespecific primers: primer FGPS6-63 (5'-GGAGAGTTAGATC TTGGCTCAG-3') and primer FGPS1509'-153 (5'-AAGGAG GGGATCCAGCCGCA-3'), which contain BglII and BamHI restriction sites (underlined), respectively. The amplified fragments were purified with a Geneclean kit (Bio 101, LaJolla, Calif.) according to the manufacturer's instructions.

Cloning. The fragments were cleaved with endonucleases $B g l \mathrm{II}$ and $B a m \mathrm{HI}$ and ligated into BamHI-restricted vector Bluescript SK ${ }^{-}$(Stratagene, La Jolla, Calif.). Plasmid purification from host strain $\mathrm{DH} 5 \alpha \mathrm{F}^{\prime}$ was performed with QUIAGEN midi-prep columns (Diagen, Düsseldorf, Germany). For most strains eight or more clones were obtained, and for $R$. palustris five clones were used; the clones were pooled for the sequencing reaction in order to obscure possible errors due to the Taq polymerase.

Sequencing. The designations of the primers used for sequencing refer to the small subunit ribosomal gene; the number is the coordinate of the $5^{\prime}$ end in the Frankia 
TABLE 1. Bacterial strains used in this study

\begin{tabular}{|c|c|c|}
\hline Strain & $\begin{array}{l}\text { Source or } \\
\text { reference }^{a}\end{array}$ & $\begin{array}{l}\text { GenBank nucleotide } \\
\text { sequence accession no. }\end{array}$ \\
\hline $\begin{array}{l}\text { Nitrobacter genomic } \\
\text { species } 2 \text { strain LL }\end{array}$ & 9 & L11661 \\
\hline $\begin{array}{l}\text { N. winogradskyi } \mathrm{W}^{\mathrm{T}} \\
\quad\left(=\mathrm{ATCC} 25391^{\mathrm{T}}\right)^{b}\end{array}$ & ATCC & L11662 \\
\hline N. hamburgensis $\mathrm{X} 14^{\mathrm{T}}$ & 1 & L11663 \\
\hline R. palustris ${ }^{\mathrm{T}}\left(=\mathrm{DSM} 123^{\mathrm{T}}\right)$ & DSM & L11664 \\
\hline
\end{tabular}

${ }^{a}$ ATCC, American Type Culture Collection, Rockville, Md.; DSM, Deutsche Sammlung von Mikroorganismen, Braunschweig, Germany.

${ }^{b} \mathrm{~T}=$ type strain.

sequence (15), and the prime refers to the primer in the opposite direction of the transcription. Twelve conserved or specific primers (FGPS6-63 and FGPS305' -78, CCAGTGTG GCCGGTCGCCCTCTC; FGPS310-20, GAGACACGGCCC AGACTCCT; FGPS594-171, GAACTGCCTTTGATACTG; FGPS700'-190, AG/ATTCCACTCA/TCCTCT; FGPS87261, CTAAAACTCAAAGGAATTGA; FGPS950'-184, GTA CTCCCCAGGCGGA; FGPS1093'-23, GCAACATAGGAC GAGGGTTG; FGPS1156-39, GACGTCAAGTCACATGC CC; FGPS1445'182, GCGATTCCAACTTCA; and primers T3 and T7 supplied by Pharmacia) were necessary to determine all of the 16S rRNA molecule on both strands. The dideoxy chain termination sequencing procedure (19) was performed by using T7 sequencing kits (Pharmacia LKB, Uppsala, Sweden).

Data analysis. Sequences were aligned by using the Clustal program (6). Previously published sequences for $B$. japonicum (26) (GenBank accession number X66024) and for strain B of $R$. palustris (27a) (GenBank accession number M59068) were added to the analysis, together with sequences of Agrobacterium tumefaciens (GenBank accession number M11223) and Escherichia coli (GenBank accession number J01695) as outgroups. Matrix pairwise comparisons were corrected for multiple base substitutions by the method of Jukes and Cantor (10). Phylogenetic trees were constructed by the neighbor-joining method (18). Gaps and regions of ambiguous sequence alignment were excluded from subsequent analyses. A bootstrap confidence analysis was performed with 1,000 replicates to determine the reliability of the tree topologies obtained (3).

\section{RESULTS}

Phylogenetic analysis. Partial 16S rRNA sequences were determined for all of the bacteria listed in Table 1 . The resulting dendrogram (data not shown) clustered $N$. winogradskyi, Nitrobacter sp. strain LL, and B. japonicum but excluded $N$. hamburgensis. This finding led us to determine the complete $16 \mathrm{~S}$ rRNA sequences for the three Nitrobacter strains and the $R$. palustris strain.

All of the complete sequences have been deposited in the GenBank data base (accession numbers are shown in Table 1). The intersequence similarity matrix and the phylogenetic tree deduced from the complete sequences are shown in Table 2 and Fig. 1, respectively. The average level of similarity determined for the Nitrobacter strains is $99.2 \%$, and the level of similarity between $N$. winogradskyi and Nitrobacter sp. strain LL is $99.6 \%$. When all of the Nitrobacter, Bradyrhizobium, and Rhodopseudomonas strains (but not the two outgroup sequences) were compared, the average level of similarity was $98.1 \%$. When
TABLE 2. Homology matrix for complete 16S rRNA sequences

\begin{tabular}{|c|c|c|c|c|c|c|c|c|}
\hline \multirow[b]{2}{*}{ Organism } & \multicolumn{8}{|c|}{ No. of differences and $\%$ homology ${ }^{a}$} \\
\hline & 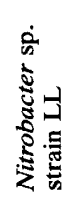 & 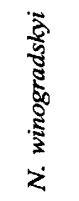 & 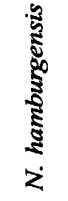 & $\begin{array}{l}\frac{3}{5} \\
\frac{5}{3} \\
\alpha \\
\alpha\end{array}$ & 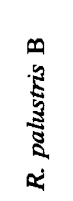 & 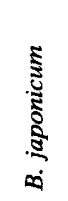 & 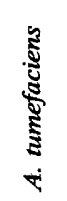 & $\begin{array}{l}\tilde{8} \\
\dot{8}\end{array}$ \\
\hline $\begin{array}{l}\text { Nitrobacter sp. } \\
\text { strain LL }\end{array}$ & & 5 & 13 & 33 & 32 & 21 & 144 & 267 \\
\hline N. winogradskyi & 99.6 & & 14 & 34 & 35 & 22 & 143 & 268 \\
\hline N. hamburgensis & 99.0 & 99.0 & & 31 & 33 & 26 & 146 & 270 \\
\hline$R$. palustris & 97.6 & 97.5 & 97.7 & & 32 & 31 & 140 & 263 \\
\hline$R$ palustris B & 98.5 & 97.3 & 98.5 & 97.6 & & 21 & 146 & 268 \\
\hline B. japonicum & 98.5 & 98.4 & 98.1 & 97.7 & 98.4 & & 147 & 272 \\
\hline A. tumefaciens & 88.7 & 88.0 & 88.5 & 89.0 & 88.1 & 88.4 & & 256 \\
\hline E. coli & 77.4 & 77.4 & 77.2 & 77.9 & 76.5 & 77.0 & 78.5 & \\
\hline
\end{tabular}

$a$ The values on the upper right are the numbers of observed differences, and the values on the lower left are the percentages of homology corrected for multiple base changes by the method of Jukes and Cantor (10).

complete sequences were used, $N$. hamburgensis clustered with the two other Nitrobacter strains, and this position was corroborated by a bootstrap analysis; $N$. hamburgensis clustered with $N$. winogradskyi and Nitrobacter sp. strain LL in $96 \%$ of the replicates. The two $R$. palustris strains exhibited a relatively low similarity level $(97.6 \%)$ and were not clustered.

\section{DISCUSSION}

The high level of sequence homology found within the genus Nitrobacter $(99.2 \%)$ confirms the proposal of Seewaldt et al. (20) that this genus is a recent group. These results also establish the fact that the genus Nitrobacter is an evolutionarily coherent group as the phylogenetic relationships agree with the relationships determined in phenotypic and genomic studies. $N$. winogradskyi and Nitrobacter sp. strain LL are more closely related than $N$. hamburgensis, a conclusion reached previously on the basis of the results of phenotypic characterization, rRNA gene polymorphism, and DNA-DNA hybridization studies (13). Phenotypically, $N$. hamburgensis is characterized by faster growth heterotrophically than autotrophically.

B. japonicum is more closely related to the genus Nitrobacter than the $R$. palustris strains are, whereas we expected the converse on the basis of rRNA-DNA hybridization data (13) and the fact that $R$. palustris cells develop an important intracytoplasmic membrane system reminiscent of the system in Nitrobacter cytoplasm. B. japonicum shares phenotypic characteristics with members of the genus Nitrobacter (for instance, its ability to denitrify, although this is a widespread characteristic). Perhaps the main difference between B. japonicum and Nitrobacter species is fixation of nitrogen, which is also a property of $R$. palustris, except that $B$. japonicum forms nitrogen-fixing nodules on leguminous plants while $R$. palustris is a free-living nitrogen-fixing microorganism.

The relatedness of $B$. japonicum and $R$. palustris was confirmed in this study by examining complete sequence data. The close relationship of these two species has been described previously on the basis of $16 \mathrm{~S}$ rRNA oligonucleotide catalogs (5), rRNA-DNA hybridization data (8) and 


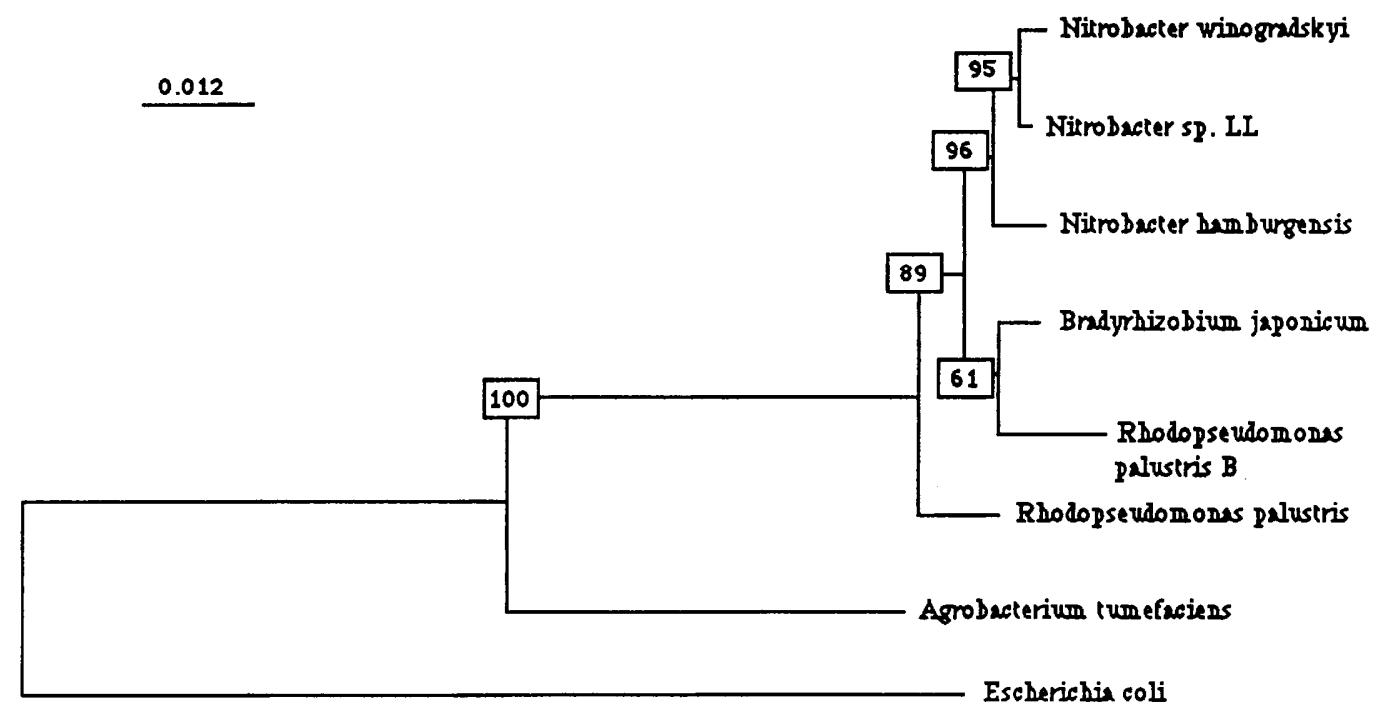

FIG. 1. Phylogenetic neighbor-joining tree based on complete $16 \mathrm{~S}$ sequences. Bar $=0.012$ substitution per site. The numbers in the boxes are the percentages of bootstrap replicates in which the cluster was found.

partial 16S rRNA sequences (28). The phylogenetic relatedness of $R$. palustris and B. japonicum led Young et al. (28), as well as Jarvis et al. (8), to suggest that it would be appropriate to group these two organisms in a single genus. However, B. japonicum differs phenotypically from $R$. palustris. According to the Ad Hoc Committee on Reconciliation of Approaches to Bacterial Systematics (25), when phylogenetic data are not consistent with phenotypic data, priority should be given to the latter (25). Young et al. argued that an important characteristic such as nitrogen fixation is shared with $R$. palustris but is not taken into account as $B$. japonicum is always compared with the genus Rhizobium and not with $R$. palustris. If a revision does reclassify $B$. japonicum and $R$. palustris as members of a single taxonomic unit (genus or family), then the genus Nitrobacter should be clustered with them too, since the average level of homology between $B$. japonicum and the three Nitrobacter species is $98.3 \%$, whereas the average level of homology between $R$. palustris and the three Nitrobacter species is 97.8\%. The genera Nitrobacter, Rhodopseudomonas, and Bradyrhizobium are phylogenetically related but do not form a phenotypically coherent group; Nitrobacter species have features in common with species belonging to the two other genera but do not fix nitrogen, which is considered a discriminative characteristic. This lack of consistency between phylogenetic and phenotypic data probably stems from the fact that some of the phenotypic characteristics taken into consideration for taxon description (nitrogen fixation, photosynthesis) are given undue weight, especially given the recent description of a photosynthetic Bradyrhizobium strain (2).

The proposal of Seewaldt et al. (20) that the emergence of the genus Nitrobacter coincided with the onset of the aerobic atmosphere on earth $\left(1 \times 10^{9}\right.$ to $1.2 \times 10^{9}$ years ago $)$ is in conflict with the value of $50 \times 10^{6}$ to $100 \times 10^{6}$ years ago obtained applying the $16 \mathrm{~S}$ rRNA molecular clock of Ochman and Wilson (16) to Nitrobacter sequences, given a "ticking" rate for the $16 \mathrm{~S}$ rRNA gene of $50 \times 10^{6}$ years for each $1 \%$ substitution per site. Considering the close relationship between Bradyrhizobium and Nitrobacter species, we speculate that the genera Nitrobacter and Bradyrhizobium evolved from a Rhodopseudomonas-like photosynthetic, nitrogen-fixing ancestor at about the time of differentiation of land plant families. One evolutionary line retained the widespread characteristic of fixing nitrogen and lost for the most part the ability to photosynthesize, while the other evolutionary line acquired the ability to nitrify and seemingly lost the ability to fix nitrogen and the ability to photosynthesize. In this context the ability of nitrogenase to reduce nitrite (23) could be a remnant of some nif gene function.

\section{ACKNOWLEDGMENT}

We thank E. Bock, Universitat Hamburg, for the gift of $N$. hamburgensis X14.

\section{REFERENCES}

1. Bock, E., H. Sundermeyer-Klinger, and E. Stackebrandt. 1983. New facultative lithotrophic nitrite-oxidizing bacteria. Arch. Microbiol. 136:281-284.

2. Evans, W. R., D. E. Fleischman, H. E. Calvert, P. V. Pyati, G. M. Alter, and N. S. Subba Rao. 1990. Bacteriochlorophyll and photosynthetic reaction centers in Rhizobium strain BTAil. Appl. Environ. Microbiol. 56:3445-3449.

3. Felsenstein, J. 1985. Confidence limits on phylogenies: an approach using the bootstrap. Evolution 39:783-791.

4. Gay, G., and A. Corman. 1984. Comparative study of the growth of two strains of Nitrobacter in batch and continuous culture. Microb. Ecol. 10:99-105.

5. Hennecke, H., K. Kaluza, B. Thöny, M. Fuhrmann, W. Ludwig, and E. Stackebrandt. 1985. Concurrent evolution of nitrogenase genes and 16S rRNA in Rhizobium species and other nitrogenfixing bacteria. Arch. Microbiol. 142:342-348.

6. Higgins, D. G., and P. M. Sharp. 1988. Clustal: a package for performing multiple alignment on a microcomputer. Gene 73: $237-244$.

7. Jarvis, B. D., H. L. Downer, and J. P. W. Young. 1992. Phylogeny of fast-growing soybean rhizobia supports synonymy of Sinorhizobium and Rhizobium and assignment to Rhizobium fredii. Int. J. Syst. Bacteriol. 42:93-96.

8. Jarvis, B. D., M. Gillis, and J. De Ley. 1986. Intra- and intergeneric similarities between the ribosomal ribonucleic acid cistrons of Rhizobium and Bradyrhizobium species and some related bacteria. Int. J. Syst. Bacteriol. 36:129-138.

9. Josserand, A., and J.-C. Cleyet-Marel. 1979. Isolation from soils 
of Nitrobacter and evidence for novel serotypes using immunofluorescence. Microb. Ecol. 5:207-213.

10. Jukes, T. H., and C. R. Cantor. 1969. Evolution of protein molecules, p. 21-132. In H. N. Munro (ed.), Mammalian protein metabolism. Academic Press, New York.

11. Lane, D. J., B. Pace, G. J. Olsen, D. A. Stahl, M. L. Sogin, and N. R. Pace. 1985. Rapid determination of 16 S ribosomal RNA sequences for phylogenetic analysis. Proc. Natl. Acad. Sci. USA 82:6955-6959.

12. Mullis, K. B., and F. A. Faloona. 1987. Specific synthesis of DNA in vitro via a polymerase-catalyzed chain reaction. Methods Enzymol. 155:335-350.

13. Navarro, E., M. P. Fernandez, F. Grimont, A. Clays-Josserand, and R. Bardin. 1992. Genomic heterogeneity of the genus Nitrobacter. Int. J. Syst. Bacteriol. 42:554-560.

14. Navarro, E., P. Simonet, P. Normand, and R. Bardin. 1992. Characterization of natural populations of Nitrobacter spp. using PCR/RFLP analysis of the ribosomal intergenic spacer. Arch. Microbiol. 157:107-115.

15. Normand, P., B. Cournoyer, P. Simonet, and S. Nazaret. 1992. Analysis of a ribosomal rRNA operon in the actinomycete Frankia. Gene 111:119-124.

16. Ochman, H., and A. C. Wilson. 1987. Evolution in bacteria: evidence for a universal substitution rate in cellular genomes. J. Mol. Evol. 26:74-86.

17. Prosser, J. L., and D. J. Cox. 1982. Nitrification, p. 178-193. In R. G. Burns and J. H. Slater (ed.), Experimental microbial ecology. Blackwell Scientific Publications, Oxford.

18. Saitou, R. R., and M. Nei. 1987. A neighbor-joining method: a new method for reconstructing phylogenetic trees. Mol. Biol. Evol. 44:406-425.

19. Sanger, F., S. Nicklen, and A. R. Coulson. 1977. DNA sequencing with chain-terminating inhibitors. Proc. Natl. Acad. Sci. USA 74:5463-5467.

20. Seewaldt, E., K. H. Schleifer, E. Bock, and E. Stackebrandt. 1982. The close phylogenetic relationship of Nitrobacter and
Rhodopseudomonas palustris. Arch. Microbiol. 131:287-290.

21. Stackebrandt, E., R. G. E. Murray, and H. G. Trüper. 1988. Proteobacteria classis nov., a name for the phylogenetic taxon that includes the "purple bacteria and their relatives." Int. J. Syst. Bacteriol. 38:321-325.

22. Tsuji, K., H. C. Tsien, R. S. Hanson, S. R. DePalma, R. Scholtz, and S. LaRoche. 1990. 16S ribosomal RNA sequence analysis for determination of phylogenetic relationship among methylotrophs. J. Gen. Microbiol. 136:1-10.

23. Vaughn, S., and B. Burgess. 1988. Nitrogenase reactivity toward nitrate and nitrite, p. 138. In H. Bothe, F. De Bruijn, and W. E. Newton (ed.), Nitrogen fixation, hundred years after. Gustav Fisher Verlag, New York.

24. Watson, S. W., E. Bock, H. Harms, H.-P. Koops, and A. B. Hooper. 1989. Nitrifying bacteria, p. 1808-1834. In J. T. Staley, M. P. Bryant, N. Pfenning, and J. G. Holt (ed.), Bergey's manual of systematic bacteriology, vol. 3. The Williams and Wilkins Co., Baltimore.

25. Wayne, L. G., D. J. Brenner, R. R. Colwell, P. A. D. Grimont, O. Kandler, M. I. Krichevsky, L. H. Moore, W. E. C. Moore, R. G. E. Murray, E. Stackebrandt, M. P. Starr, and H. G. Trüper. 1987. Report of the Ad Hoc Committee on Reconciliation of Approaches to Bacterial Systematics. Int. J. Syst. Bacteriol. 37:463-464.

26. Willems, A., and M. D. Collins. 1992. Evidence for a close genealogical relationship between Afipia (the causal organism of cat scratch disease), Bradyrhizobium japonicum and Blastobacter denitrificans. FEMS Microbiol. Lett. 96:241-246.

27. Woese, C. R. 1987. Bacterial evolution. Microbiol. Rev. 51:221271.

27a.Woese, C. R. Unpublished data.

28. Young, J. P. W., H. L. Downer, and B. D. Eardly. 1991. Phylogeny of the phototrophic Rhizobium strain BTAil by polymerase chain reaction-based sequencing of a 16S rRNA gene segment. J. Bacteriol. 173:2271-2277. 